\title{
Asociaciones y cooperativas rurales: factores internos y externos que influyen en su estabilidad y eficiencia. Una reflexión sobre el caso de Viotá, Cundinamarca
}

\author{
Cristhian Camilo Narváez-Rodríguez
}

* Magíster (c) en Estudios Políticos, Instituto de Estudios Políticos y Relaciones Internacionales (IEPRI), Universidad Nacional de Colombia. Profesor, Universidad Piloto de Colombia, Bogotá, Colombia. Correo electrónico: ccnarvaezr@unal.edu.co

Recibido: 19 de febrero del 2014 Aprobado: 8 de mayo del 2014

Cómo citar este artículo: NarváezRodríguez, C. C. (2014). Asociaciones y cooperativas rurales: factores internos y externos que influyen en su estabilidad y eficiencia. Una reflexión sobre el caso de Viotá, Cundinamarca. Cooperativismo \& Desarrollo, 104(22), 63-81. doi: http://dx.doi. org/10.16925/co.v22i104.971

\begin{abstract}
Resumen
El desarrollo de asociaciones y cooperativas rurales eficientes y con vocación de largo plazo es un pilar fundamental para el desarrollo agrícola en Colombia. Por tanto, el trabajo indaga sobre los factores internos y externos referentes a estas organizaciones, que afectan su vocación de permanencia y eficiencia en el contexto rural nacional. Los factores internos se refieren a la capacidad de la gerencia de estas organizaciones de manejar, de la mano con los asociados, la organización de la mejor manera. Los factores externos tienen que ver con los niveles de estabilidad institucional y confianza interpersonal que existan en las comunidades en que estas organizaciones operan. Asimismo, el documento hace una reflexión sobre la situación de tres asociaciones rurales en el municipio de Viotá (Cundinamarca) de acuerdo con algunos de los factores enunciados.
\end{abstract}

Palabras clave: asociaciones rurales, eficiencia, estabilidad institucional, firmas.

Rural Associations and Cooperatives: Internal and External Factors That Influence Their Stability and Efficiency. A Reflection on the Case of Viotá, Cundinamarca

\begin{abstract}
The development of efficient rural cooperatives with staying power over the long term is a fundamental element for agricultural development in Colombia. This research therefore looks at internal and external factors associated with such organizations, which affect their permanence and efficiency in the national rural context. The internal factors refer to the management capacity of these organizations to better handle organization, jointly with their associates. The external factors involve levels of institutional stability and interpersonal trust in the communities where the organizations operate. The document also reflects on the situation of three rural associations in the municipality of Viotá (Cundinamarca) in accordance with some of the referred-to factors.
\end{abstract}

Keywords: rural associations, efficiency, institutional stability, firms.

Associações e cooperativas rurais: fatores internos e externos que influenciam em sua estabilidade e eficiência. Uma reflexão sobre o caso de Viotá, Cundinamarca

\section{Resumo}

O desenvolvimento de associações e cooperativas rurais eficientes e que tendem a ser de longo prazo é um pilar fundamental para o desenvolvimento agrícola na Colômbia. Portanto, este trabalho indaga sobre os fatores internos e externos referentes a essas organizações, que afetam sua tendência de permanência e eficiência no contexto rural nacional. Os fatores internos referem-se à capacidade de gestão dessas organizações de operar, de mãos dadas com os associados, a organização da melhor maneira. Os fatores externos estão relacionados com os níveis de estabilidade institucional e confiança interpessoal que existam nas comunidades em que essas organizações operam. Desse modo, o documento faz uma reflexão sobre a situação de três associações rurais no município de Viotá (Cundinamarca) de acordo com alguns dos fatores enunciados.

Palavras-chave: associações rurais, eficiência, estabilidade institucional, assinaturas. 


\section{Introducción $^{1}$}

El presente artículo no pretende elaborar un modelo explicativo sobre las causas necesarias y suficientes para el desarrollo de asociaciones y cooperativas campesinas competitivas. Se circunscribe a presentar un marco teórico que permita abordar la naturaleza de estas organizaciones y ordenar los factores internos y externos más relevantes que afectan su desarrollo. Este esquema analítico separa los factores entre: 1 ) internos a la organización, referidos a las capacidades gerenciales que afectan funcionamiento eficiente de esta en el logro de sus fines gremiales o empresariales; y 2) elementos externos a la organización, relacionados con el entorno en el cual esta se desarrolla, como la estabilidad institucional, representada en la estructura agraria, y los niveles de confianza, reciprocidad y cooperación en las comunidades rurales, representada en el capital social rural (Foronda-Robles y Galindo-Pérez de Azpillaga, 2012), los cuales impiden o permiten a la organización tener vocación de largo plazo. Es decir, la competitividad, eficiencia y perdurabilidad de estas organizaciones rurales no solo dependen de las habilidades gerenciales y el liderazgo de sus directivas; también existen unas condiciones externas en las cuales se crea la asociación o cooperativa, y estas condiciones limitan y a la vez perfilan a la organización.

La primera sección define a las organizaciones rurales objeto de estudio, sus diferencias y similitudes. Se establecerá que las asociaciones de productores y las cooperativas campesinas operan como firmas $^{2}$, de acuerdo con la definición de Coase (1937), es decir, surgen como organizaciones que buscan centralizar actividades y minimizar los costos de transacción globales de la economía. La aplicación del concepto de firma a las cooperativas ha sido propuesta por un amplio grupo de investigadores; entre los primeros está CastroRodríguez (1963) y, en Colombia, está Dávila (2004).

\footnotetext{
1 Este estudio fue desarrollado en el marco del macroproyecto Diseño, implementación, gestión y proyección de la Investigación y Desarrollo (I\&D) del "Programa Piloto para la conformación de proyectos productivos en el Centro y Occidente de Cundinamarca, epicentro Viotá: Potencializando la Ciudad Región", ejecutado por la Universidad Piloto de Colombia.

2 El término firmas (en inglés, firms) es utilizado por disciplinas como el derecho, la administración y la economía para definir diversas formas de organización social y económica. En el presente texto, ese término se utilizará exclusivamente según la definición aportada por la escuela neoinstitucionalista de las ciencias económicas a través de autores clásicos de este enfoque microeconómico como Coase (1937), Alchian y Demsetz (1972), Williamson (1989) y Ostrom (2000).
}

Este artículo propone ampliarlo a las asociaciones de productores, siempre que estas transfieran a sus asociados nuevas tecnologías (herramientas o técnicas para el mejoramiento de los procesos productivos), y para ello deban adquirirlas en el mercado a costos inferiores que los que asumiría cada campesino por separado. Al establecer que las organizaciones rurales objeto de estudio son firmas, se deduce que, primero, se crean a partir de un contrato o acuerdo de largo plazo; este acuerdo surge en comunidades con instituciones estables y con altos grados de confianza (Ostrom, 2000; North, 1990); segundo, se ven obligadas al aumento de su productividad interna y a la consecutiva reducción de los costes de gerencia para permanecer en el tiempo (Alchian y Demsetz, 1972).

En la segunda sección se describen los factores externos e internos que influyen en la estabilidad y desarrollo de las asociaciones rurales objeto de estudio. La "estructura agraria" y el "capital social rural", son los factores considerados en el medio rural y que influyen de manera directa en los niveles de asociatividad campesina. Por otra parte, las estructuras de la alta gerencia (que relacionan a los asociados con la gerencia), la existencia o no de free riders y las capacidades gerenciales para medir y controlar la productividad de la organización, para generar cohesión y redes de valor, son los factores internos que afectan su desempeño.

La tercera sección del trabajo detallará el estado de las asociaciones campesinas encontradas en Viotá, Cundinamarca, la estructura agraria del municipio y el estado de las familias rurales. Estas descripciones parten de una serie de encuestas realizadas en campo a los productores de la región y a los presidentes de tres asociaciones, de la mano con los informes sobre el estado de la estructura agraria en la región. Este artículo es resultado del marco del proyecto mencionado, el cual, a través del trabajo interdisciplinar, analiza los procesos comerciales, financieros y medioambientales de las familias campesinas de la región. Por lo anterior, el presente trabajo debe comprenderse como un aporte más desde la teoría organizacional a todo un conjunto de estudios realizados por diferentes profesionales sobre el pasado, el presente y prospectiva del municipio. A manera de cierre, se presentará un balance entre los factores internos y externos presentados a lo largo del trabajo; una reflexión sobre la importancia de la estabilidad institucional en el campo y el papel del empoderamiento campesino para el desarrollo de la competitividad rural. 


\section{Las asociaciones y cooperativas de campesinos}

Dos de las formas de aglomeración y organización rural más comunes son las cooperativas y las asociaciones de productores campesinos. El primer objetivo de esta sección es definirlas a partir de sus particularidades y de sus elementos en común. En esta parte se prestará especial atención al modelo empresarial cooperativista (opuesto en muchos sentidos al modelo capitalista de empresa), a los efectos económicos y sociales que este genera en las comunidades donde se ha desarrollado y profundizado, representados en niveles de distribución de la riqueza y alto grado de cooperación social. Se presentarán algunos trabajos que indagan sobre modelos exitosos de promoción del cooperativismo en América Latina y una breve reflexión del caso colombiano. Finalmente, se establecerá una analogía entre estas formas organizacionales y el concepto de "firma", desarrollado por Coase (1937) y estudiado por la escuela neoinstitucionalista de la organización industrial, el cual está guiado por los conceptos de "costo de transacción", "coste de gerencia", "acuerdos institucionales" y la "estabilidad institucional" expuestos por Coase (1937), Alchian y Demsetz (1972), Ostrom (2000) y North (1990) en una serie de estudios clásicos de esta escuela económica. La conclusión del argumento es que las cooperativas y las asociaciones operan como "firmas", de lo cual se sigue que, primero, su permanencia depende de que logren ser más eficientes que el mercado asignando recursos, y segundo, su fundación y estabilidad dependen de la existencia de una comunidad estable y capaz de diseñar e implementar acuerdos institucionales en el largo plazo.

Las asociaciones de productores rurales se entenderán como organizaciones privadas, con vocación de largo plazo y establecidas como personas jurídicas ${ }^{3}$. Estas aglomeran a un conjunto de productores rurales, las cuales comparten al menos un rasgo en común (regiones o tipos de cultivo), y se forman típicamente con el objetivo de mejorar el estado de las unidades productivas asociadas, ya sea a través del cabildeo político y de las relaciones públicas (con organizaciones públicas como privadas), o de procesos de transferencia

3 El concepto de asociación es amplio a través de múltiples disciplinas; sin embargo, dados los objetivos del presente trabajo, se limita exclusivamente a asociación concebida como la organización (denominada así mismo corporación) establecida como persona jurídica sin ánimo de lucro y regulada por el Código Civil Colombiano y la Ley 22 de 1987. tecnológica a los asociados con los fondos mutuos, creados por estos. Sobre las actividades de cabildeo político y relaciones públicas, su objetivo es desarrollar alianzas con entidades públicas o privadas. Ante las entidades públicas, su objetivo principal es participar en las estructuras políticas y regionales, representar a los productores asociados; en relación con las entidades privadas, preferencialmente buscan alianzas enfocadas en la transferencia tecnológica o la financiación de los diferentes procesos agrícolas de sus asociados.

Sobre las actividades de transferencia tecnológica, estas pueden ir desde la compra y distribución de insumos o herramientas (fertilizantes, abonos, guadañas, entre otros), hasta capacitaciones en mejores técnicas en siembra, cultivo y venta o entrega de semillas, $y$, en general, abarcan un amplio conjunto de acciones enfocadas en el mejoramiento de los procesos de producción de las parcelas asociadas. Las asociaciones de productores se crean y operan como organizaciones solidarias; es decir, no buscan el lucro como propósito principal: en el caso de obtener excedentes económicos por sus actividades, estos deben ser reinvertidos en la organización, no pueden ser apropiados por la gerencia (como sucede en las firmas capitalistas con las bonificaciones por productividad), ni por sus asociados (como sucede en las firmas capitalistas con los dividendos).

Por su parte, las cooperativas rurales son típicamente definidas como "empresas con sentido social", donde los propietarios son a la vez trabajadores, es decir "autogestionadas" y con vocación de desarrollo comunitario (IICA, 2010). Son empresas, dado que su objetivo es la producción, comercialización, transformación y distribución de bienes y servicios compitiendo con firmas con ánimo de lucro, con estándares de productividad y competitividad de mercado. A la vez, las cooperativas tienen fines sociales: los excedentes logrados en el ejercicio de las actividades comerciales no se dirigen como dividendo a sus asociados, sino que se reinvierten en la organización o se destinan a proyectos comunitarios, cívicos o humanistas (educación, cultura, recreación, desarrollo personal y comunitario, atención a comunidades pobres o necesitadas, entre otros). El modelo cooperativo es, por lo anterior, un modelo de empresa cuya eficiencia se debe redirigir a la sociedad:

Una cooperativa es una asociación de mujeres y hombres que aúnan sus esfuerzos para constituir una empresa de la que tienen la propiedad común, que se rige por reglas democráticas y que persigue otros fines además 
de la rentabilidad. Las cooperativas anteponen las personas a las ganancias, y también ayudan a sus miembros a hacer realidad sus aspiraciones sociales, culturales y económicas comunes. Una cooperativa es una empresa social que promueve la paz y la democracia (FAO, 2012).

O de acuerdo con la International Co-operative Alliance (s. f.):

A co-operative is an autonomous association of persons united voluntarily to meet their common economic, social, and cultural needs and aspirations through a jointly owned and democratically-controlled enterprise.

Además de las diferencias filosóficas entre los modelos de empresa capitalista y cooperativista, se pueden resaltar las siguientes: primero, en el modelo cooperativista, los excedentes de la empresa se reinvierten en la organización, no pueden ser apropiados por los asociados a manera de dividendos, ni por la gerencia a manera de bonificación por productividad, como sí ocurre en el caso de la empresa capitalista. En segundo lugar, los asociados en la organización cooperativa participan de manera democrática y equitativa en las asambleas (un voto por persona), a diferencia de las empresas capitalistas, donde las decisiones dependen del denominado "poder accionario" (un voto por acción, independientemente de la cantidad de acciones que pueda tener una persona). Finalmente, el modelo cooperativista promueve la integración de los asociados en los procesos de la organización, es decir, quienes aportan capital aportan también trabajo para el funcionamiento de la misma (siendo así asociado a la vez que empleado); paralelamente, en la empresa capitalista los socios aportan el capital, y su remuneración por el aporte es un dividendo, no un salario (es decir, se remunera la productividad del capital invertido, no el trabajo).

Estas características del diseño de la empresa cooperativa generan una serie de consecuencias (las cuales se pueden trasponer a las asociaciones rurales). En primer lugar, el hecho de que los excedentes generados por la cooperativa, resultado de sus actividades empresariales y comerciales, deban ser reinvertidos en la organización y no puedan ser apropiados por su gerencia, lleva a que, según Alchian y Demsetz (1972), los niveles de productividad del gerente cooperativista sean más bajos que los de sus colegas de empresas privadas. Esta teoría expresa que el principal incentivo que tiene un gerente para aumentar la productividad de la organización industrial es la llamada bonificación por productividad, derecho que la junta de asociados le otorga al gerente sobre una parte de las utilidades generadas por la empresa (denominados "derechos sobre el residual"): a mayor productividad, reflejada en los beneficios de la organización, mayor bonificación para el gerente. Este incentivo desaparece en la empresa cooperativa; por ello se esperaría que el remoloneo (holgazanería) por parte del gerente de una organización cooperativa ( $\mathrm{y}$ en general cualquier organización solidaria) fuera superior. Sin embargo, los mismos autores rescatan el espíritu de lealtad y de equipo como un factor que puede aportar a los incrementos en productividad, generados por el gerente, independientemente de la existencia o inexistencia de derechos sobre una parte de las utilidades.

En segundo lugar, el sistema de toma de decisiones en las empresas cooperativas (un asociado, un voto), creado para privilegiar los intereses de las personas, independientemente de la cantidad de recursos aportados, puede ser la base para fundar formas de aglomeración del poder dentro de las cooperativas: la creación de facciones internas que promuevan sus intereses "premiando" o "castigando" a los asociados, según si estos apoyaron o no sus proyectos es un resultado posible; estas son denominadas facciones de poder burocrático (o "roscas" en el lenguaje común) (Rodríguez-Vargas, 1998). Igualmente podría generar efectos en los asociados más ricos o con mayor capacidad económica, incentivándolos a tomar la decisión personal de aportar un valor igual a los asociados con capacidad de ingreso promedio y no de acuerdo con su capacidad; esto, dada la poca representación que podrían tener en la toma de decisiones colectivas con aportes superiores al promedio (Centner, 1988; FAO, 2012).

Las cooperativas agrícolas están conformadas típicamente por familias campesinas, y se dedican principalmente a la producción conjunta, a la transformación de los bienes agrícolas, a la comercialización de estos o a la comercialización de insumos agrícolas a sus asociados. Para el desarrollo de estas actividades, las cooperativas requieren una serie de activos (centros de acopio, camiones, bodegas, despulpadoras, etc.), que se dispondrán para su explotación en el largo plazo, y una estructura administrativa que promoverá su productividad. Según Castro-Rodríguez (1963, p. 108), las condiciones generales para que una cooperativa tenga éxito son: primero: "Aumentar los ingresos que obtienen los socios por la venta de sus productos"; segundo: "Reducir el precio o mejorar la calidad de los artículos comprados por los socios", y tercero: "Ofrecer nuevos 
y mejores servicios, o dar un trato más equitativo a los socios"; en resumen, "aumentar el bienestar económico de sus asociados" a través de actividades empresariales, de mercado. En general, las cooperativas rurales exitosas son agentes transformadores y organizadores del campo, en la medida en que: mejoran el acceso de los productores al mercado, estandarizan productos, estabilizan los ingresos de los asociados (reduciendo la pobreza), aumentan el poder de negociación de las familias campesinas ante compradores y proveedores, reducen los riesgos de mercado del sector agrícola gracias a la diversificación de productos y el desarrollo de valores agregados, e igualmente generan beneficios sociales y políticos como el trabajo en equipo y el empoderamiento de las comunidades rurales (CastroRodríguez, 1963).

En América Latina se pueden evidenciar experiencias exitosas en la aplicación y desarrollo del modelo cooperativista, representadas en apropiación de nuevas tecnologías, desarrollo de modelos de negocio sostenibles en el tiempo y en aumentos de la cohesión social, reducción de la pobreza y empoderamiento comunitario $^{4}$ (Mendoza, Gutiérrez, Pedraza y Fernández, s. f.; IICA, 2010; IICA, 2013a), las cuales tienen en común:

4 Es importante resaltar el trabajo desarrollado por el IICA (2013a), en el que compara las experiencias de nueve países de América Latina en procesos de desarrollo del cooperativismo rural. Todos estos casos señalan los impactos que las cooperativas rurales pueden lograr al ingresar a mercados locales e internacionales, desarrollando innovación tecnológica y valores agregados, empoderando social y políticamente a los campesinos, y promoviendo el desarrollo económico de las comunidades. En su estudio, el IICA resalta la importancia de la conjunción de diferentes actores en el fortalecimiento del cooperativismo, como lo son los centros de desarrollo tecnológico, las universidades, las organizaciones estatales de promoción de la agricultura y las entidades financieras. Finalmente, el trabajo describe los procesos a través de los cuales estas empresas cooperativistas han desarrollado innovaciones en producto, procesos, mercado y organizacionales, de manera análoga a como las grandes empresas multinacionales del agrobussiness las desarrollan. Esto ha demostrado que el modelo cooperativo puede competir "cabeza a cabeza" con estas organizaciones con ánimo de lucro en desarrollo y comercialización de nuevas tecnologías. Los ejemplos más sobresalientes son: la creación de cooperativas capaces de producir y comercializar sus propios fertilizantes (Bolivia), el desarrollo de especies más resistentes y productivas (caso del trigo Yampara de Bolivia, que se desarrolló después de 14 años de investigación) o la introducción al mercado de productos nuevos y exóticos (como la papa ecuatoriana). Estos tres casos demuestran avances tecnológicos y en las estructuras de comercialización, que al vincular especialistas en propiedad intelectual y desarrollo tecnológico generan innovaciones en la frontera de la técnica agrícola con fines comerciales. Estos avances fueron apropiados por las sociedades cooperativas, y por transitividad pertenecen a un conjunto de pequeños campesinos. Tales procesos de innovación requieren en general un fuerte apoyo estatal (no paternalista), una comunidad fuertemente cohesionada que se aglomere y trabaje en equipo, y una cooperativa estratégicamente aliada con los mercados, el sector privado y la academia en función de la competitividad rural (IICA, 2013a, pp. 210 y ss).
- Son procesos de largo plazo y progresivos: el fortalecimiento de las asociaciones rurales se desarrolla en plazos de más de una década de acompañamiento a las comunidades. Asimismo, este acompañamiento se realiza con objetivos diferentes de acuerdo con el tamaño y la etapa en la cual se encuentre la organización rural. A manera de ejemplo, en el caso nicaragüense (Mendoza et al., s. f.), la primera década se enfocó en la mejora de calidades y productividades; posteriormente se desarrollaron valores agregados e ingreso a mercados especializados; paralelamente a estos procesos se llevaron a cabo actividades para el fortalecimiento de la cohesión social entre los asociados.

- La existencia de institucionalidad estatal enfocada al asociativismo rural: el Estado ha desarrollado una serie de instituciones y políticas específicas para la promoción y el desarrollo de organizaciones rurales (IICA, 2010). Estas van desde entidades de formación y educación en asociatividad y cooperativismo, instituciones para la investigación y desarrollo de tecnologías agrícolas, banca especializada (para adquisición de capital de trabajo y activos fijos), entidades de asesoría y apoyo en diseño y gestión de proyectos agrícolas, hasta políticas de acceso a bienes y servicios estatales con precios subsidiados e infraestructura para mejorar la competitividad (vías, TIC).

Sobre el papel del Estado en la promoción de asociaciones rurales, estos trabajos hacen énfasis en la necesidad de establecer políticas enfocadas en la mejora de la productividad, que a la vez fortalezcan las capacidades de autorganización y autonomía en estas (IICA, 2010); lo anterior a causa de experiencias en las que existen fuertes tensiones entre la promoción del asociativismo rural contra intereses de cooptación y captura de estas organizaciones por facciones políticas.

- Existe una red entre el Estado, la academia y el mercado enfocada en la productividad: el trabajo conjunto y en red entre el Estado (específicamente las instituciones rurales del Estado), la academia (centros de investigación y transferencia en tecnologías blandas y duras) y el mercado (acceso a competidores y consumidores) es resaltado en las experiencias exitosas en América Latina (IICA, 2013a).

Sobre el papel del cooperativismo rural en Colombia, específicamente en el siglo xx, Rodríguez-Vargas (1998) establece que ha participado en las tensiones 
políticas y académicas alrededor de "la cuestión agraria”; así mismo, en la década de los noventa, este modelo sufrió un desgaste por diversos motivos sociales, económicos y gerenciales. En cuanto a las tensiones políticas que han rodeado el cooperativismo, Rodríguez-Vargas establece (siguiendo a Antonio García) que, siendo el cooperativismo rural un mecanismo de empoderamiento político y una forma de acceso al desarrollo económico por parte de las familias rurales que no se opone al sistema capitalista, ni enfrenta a las estructuras del Estado, ha generado ciertos niveles de desconfianza en las élites rurales y nacionales. Estas tensiones se acrecentaron con la implementación de modelos cooperativistas en el campo como medios de control social, influenciados por Estados Unidos en el marco de las políticas conocidas como La Alianza para el Progreso.

Por ejemplo, Rodríguez-Vargas recuerda la opinión de Orlando Fals Borda sobre estas políticas de desarrollo cooperativista, como herramientas neocoloniales que, por su diseño y forma de implementación, limitarían la evolución de las transformaciones de fondo que requerían (y requieren) los territorios rurales, históricamente excluidos del orden político y del desarrollo económico. Este tipo de políticas, implementadas como respuesta del Estado a las demandas de los campesinos de paz y de acceso al desarrollo económico, tuvieron sus efectos en la legitimidad del modelo cooperativista. Así mismo, es importante resaltar el papel de organizaciones como la Iglesia en el desarrollo de empresas cooperativas; este fenómeno se dio en toda América Latina (Coque-Martínez, 2002), y en Colombia, especialmente en Santander (Dávila, 2004). La importancia de pertenecer a la misma comunidad religiosa fue un rasgo integrador de la comunidad para establecer empresas comunitarias de largo plazo; sin embargo, las posibilidades de exclusión de campesinos no pertenecientes a la Iglesia, o el desarrollo de estos modelos en determinadas zonas para reforzar la influencia de esa institución o reducir la de otros movimientos religiosos o políticos, son temas de necesaria revisión.

Los desgastes del modelo cooperativo en los noventa, que minan su legitimidad y la ideología cooperativista misma, según Rodríguez-Vargas (1998), tienen su origen en dos factores: en primer lugar, las grandes crisis de esa década - la crisis del UPAC y la financieraminaron las posibilidades del modelo cooperativista de ahorro y crédito, de adaptarse a las condiciones del juego de la apertura; en segundo lugar, los malos manejos, la corrupción, los sistemas de gestión mal diseñados y obsoletos impactaron la legitimidad del sistema cooperativista de empresa. Todo esto durante la implementación del discurso de la apertura que entroniza al modelo privado de empresa como el más eficiente y racional, frente a los modelos empresariales públicos y solidarios. Estos problemas de legitimidad van de la mano con la debilidad de las cooperativas de segundo y tercer nivel, y de las confederaciones de cooperativas para promover políticas a favor del movimiento y la profesionalización de este tipo de organizaciones.

A pesar de los problemas del modelo cooperativista en Colombia, en otros entornos este ha demostrado ser un generador de grandes beneficios sociales y económicos. Algunos de los beneficios de la asociatividad, según León (2010), y hacia los cuales las organizaciones estudiadas (cooperativas y asociaciones de productores rurales) se dirigen son: el desarrollo de economías de escala, aumento de la fuerza de negociación, generación de valores agregados, aumento de la capacidad de financiación, reducción de costes de cada unidad productiva, promoción, transporte y gestión conjunta, y acceso a asesoría especializada ${ }^{5}$; es decir, que estas organizaciones buscan para los asociados campesinos y sus mercados mejores condiciones en precios y calidades, o de acuerdo con el término acuñado por los neoinstitucionalistas, mejorar la eficiencia del mercado, reduciendo los costos de transacción (Coase, 1937). Por lo anterior se puede asumir que las asociaciones de campesinos y las cooperativas operan como firmas (firms).

\section{Factores externos e internos a la organización rural que impactan su vocación a largo plazo y su eficiencia interna}

\section{Factores externos a las organizaciones rurales}

El entorno externo a la firma puede ser comprendido de dos formas: en primer lugar, como la comunidad en la cual la firma se funda, y a partir de la cual se determina su capacidad y posibilidad de permanencia (Ostrom, 2000): en segundo lugar, como el conjunto de relaciones de mercado que la firma transformará si

Para conocer estudios de caso sobre modelos cooperativistas que han generado estos efectos, se sugiere revisar los trabajos del IICA (2013a y 2013b). 
logra funcionar eficientemente (Demsetz, 1997). En el medio rural, donde las cooperativas y asociaciones de productores se fundan, esto se traduce en la "estructura agraria", que describe los actores y las "reglas del juego" del campo colombiano. Para estudiar la estructura agraria y su estabilidad en el entorno nacional, se presentarán los actores que han participado en su constitución. Finalmente, se establecerá una relación entre la estabilidad de la estructura agraria y el capital social rural, enfocado en los efectos sobre las asociaciones y las cooperativas campesinas.

Como describe el PNUD (2011), la estructura agraria está compuesta por cuatro elementos: la tenencia de la tierra, el uso productivo que se le dé al suelo, las formas de relación laboral y social en torno a la tierra, y las relaciones entre el campo y el mercado, el campo y el Estado (en general, con el sistema político). Es de destacar que quienes establecen las reglas sobre estos cuatro elementos imponen un orden sobre el sector rural, y en consecuencia son quienes lo perfilan. En Colombia, estos actores son varios y de diversa índole: el Estado, las élites rurales, los actores armados, las multinacionales y, por supuesto, las numerosas familias campesinas micropropietarias, entre otros (Fajardo, s. f.). En general, se acepta que el Estado ha sido débil e incoherente para establecer orden sobre los cuatro elementos de la estructura rural; prueba de ello es que ha fallado consecutivamente en sus esfuerzos de llevar a cabo una reforma agraria integral, y no ha intervenido las estructuras de poder y control de la tierra. Como consecuencia de lo anterior, varias de las zonas rurales del país poseen estructuras agrarias atrasadas (Fajardo, s. f., p. 181).

Entre los actores que más han influido en la estructura agraria nacional, están los grupos armados y los narcotraficantes, que han generado una latifundización creciente, a la vez que minifundios cada vez más pequeños mediante la violencia y el narcotráfico $(\mathrm{Fa}-$ jardo, s. f.). Los altos precios de la cocaína en mercados internacionales han llevado a los campesinos, actores armados y "narcos" a ampliar la frontera agrícola, destruir otros cultivos y dedicarse principalmente a la coca en el afán de participar "del negocio" en algunas zonas del país. Alrededor de este cultivo se generan sus propias estructuras de trabajo y de poder, que impactan a las familias campesinas, a las élites rurales, a los actores armados e, incluso, a los poderes nacionales.

Las grandes empresas extranjeras han ingresado al campo colombiano promovidas por el Estado para generar inversión directa. La promesa de entrada ha sido que estas serán capaces de explotar la riqueza del campo y aumentar su productividad, de lo cual el Estado colombiano y las regiones obtendrán beneficios económicos, laborales y sociales. Sin embargo, el débil papel del Estado en la regulación de estas relaciones, de la mano con su alta dependencia de las rentas capturadas por estas actividades, ha permitido que estas empresas impongan su propio orden en el campo, transformando las relaciones laborales, la tenencia de la tierra, el uso del suelo (por ejemplo, a través de las tensiones entre minería y agricultura) y aumentando las tensiones sociales.

Las élites rurales, en general, han sido conservadoras de la estructura agraria (PNUD, 2011). En los momentos de reforma, estas élites han dilatado su implementación en las regiones, e igualmente han tenido acceso directo al Gobierno Nacional a través de las estructuras de poder regional y de asociaciones rurales que han logrado establecerse como grupos de presión política. La evolución de las relaciones entre los grupos armados, las multinacionales, las élites rurales y el Estado difiere de región a región: las alianzas, las redes de influencia y los usos del suelo se transforman estableciendo diferentes intereses políticos en los modelos de desarrollo agrario a lo largo del país.

Las familias campesinas han desempeñado un papel marginal en el desarrollo de reglas en la estructura agraria. En general, los movimientos políticos agrarios han sido marginalizados y deslegitimados, haciéndolos ver afines a la subversión armada y al terrorismo: en el discurso los demás integrantes de la estructura agraria reconocen que las familias campesinas requieren representación. Sobre lo anterior, varios gobiernos han tratado de crear estructuras de representación de las familias campesinas, ordenadas desde la ley; por ejemplo, la Asociación Nacional de Usuarios Campesinos (ANUC), en el gobierno de Carlos Lleras Restrepo, o las Zonas de Reserva Campesina (ZRC), creadas en el gobierno de César Gaviria. Sin embargo, su existencia ha generado en los actores políticos interpretaciones extremistas: subversivas (representan directamente a los intereses de los grupos armados), o por el contrario, institucionales, es decir, son modos de control de la protesta social por parte del establecimiento político (ILSA, 2012; Osejo-Varona, s. f.). Aun con estos mecanismos de representación institucional, cuya legitimidad está constantemente en entredicho por los actores de uno u otro lado del espectro político, las familias campesinas siguen en la mitad de la guerra, sin acceso al desarrollo económico y político (Perfetti, 2009), y como el actor más vulnerable en la conformación de la estructura agraria. 
Sobre el Estado como regulador de las relaciones en el campo, se afirma que ha sido incoherente y carente de una visión rural incluyente de largo plazo (Rivera, 1999), a la vez que se acepta el papel determinante que ha tenido el modelo de desarrollo aperturista en la reconfiguración de la estructura rural. El modelo de industrialización por sustitución de importaciones desarrolló una serie de políticas comerciales que protegían al sector rural de la competencia externa junto a una serie de instituciones estatales para la promoción del campo (con tamaño y alcance limitados); posteriormente, con la entrada del modelo aperturista, las barreras comerciales fueron eliminadas y esta institucionalidad rural fue acabada (Restrepo. 2011). En este proceso no se implementaron políticas de transición al nuevo modelo, como las propuestas por Bejarano (1998), dejando a los pequeños productores agrícolas expuestos a la competencia internacional y a las principales variaciones de los mercados internacionales (descritas por Nash, 2011).

El objetivo de estas políticas, según sus promotores, es llevar las productividades del sector privado interno a los niveles de competencia internacional; esto se conoce como el "ajuste de productividades". Sin embargo, después de más de dos décadas de implementación del modelo, el "ajuste de productividades" en el sector rural no se ha dado; por el contrario, la participación del sector como parte del PIB se ha reducido, y sus crecimientos anuales están por debajo del promedio nacional; los pequeños productores vieron sus ingresos menguados y su participación en el comercio interno, reducida (Perfetti, 2009). Los defensores del modelo indican que estos resultados se deben a una implementación incompleta de la apertura; por tanto, proponen seguir desmontando los sistemas de nivelación de precios y las barreras comerciales aún existentes (Gómez, 2011).

Según otros analistas, la intervención del Estado debe dirigir a los productores hacia: primero, evitar competir con cultivos en los que se tengan "desventajas estructurales" como país, y dirigir la política de incentivos a productos en donde este pueda ser más competitivo (Reina, Zuluaga, Bermúdez y Oviedo, 2011), independientemente de que se pierdan cultivos de la canasta básica que garantizan la seguridad alimentaria (como el arroz, la papa o el trigo), pues serán suplidos por oferentes internacionales; segundo, diversificar la oferta y generar valores agregados, ingresando a mercados exclusivos, exóticos, y certificados como gourmet, orgánicos o fair trade (Gómez, 2011; Reina et al.,
2011; Perfetti, 2011; Hellin y Higman, 2002). De la mano de estas propuestas, está la necesaria inversión en infraestructura como requisito mínimo para alcanzar el "ajuste de productividades" (Nash, 2011).

Por su parte, Restrepo (2011) argumenta que la política arancelaria y comercial por sí sola no hará del sector agropecuario productivo y competitivo per se: "Las cosas no son tan sencillas, y simplemente cambiando el switch en la política arancelaria todo estaría arreglado" (Restrepo, 2011, p. 11): no todo es cuestión de desmontar o reducir los aranceles, pues "prácticamente son cero". Ese autor señala que el desarrollo rural pasa por el restablecimiento de políticas sobre la tenencia de la tierra, el rediseño de la institucionalidad que promovía el desarrollo del sector y la infraestructura productiva (riegos y drenajes, así como carreteras). Restrepo (2011) afirma que con la apertura comercial "se destruyó la institucionalidad encargada de manejar el desarrollo rural en Colombia” (p. 21).

Finalmente, el Ministerio de Agricultura y Desarrollo Rural (2006), alineado con el modelo de desarrollo, promueve una política para el sector rural enfocada en la exportación, delimitando los productos por exportar, y los territorios donde se priorizará la transformación de cultivos.

Como conclusión parcial, se observa que las políticas lesivas a los productores son expeditas y directas (como el desmonte de aranceles, los tratados de libre comercio y el desmonte de la institucionalidad rural), mientras que las políticas que les permitirán acceder al modelo de desarrollo son de lenta implementación, y los sobrecostos de la adaptación van por cuenta de los productores campesinos. Una evidencia de esto es que la participación del sector agrícola en el PIв ha decrecido desde la apertura (Misas, 2002; Perfetti, 2009), y, aunque el campo se pacifique (considerando el proceso de paz en curso), las tensiones económicas y políticas de fondo siguen exigiendo intervención del Estado.

De esta manera, se advierte que los derechos al suelo, su uso, el acceso al mercado y al establecimiento político, impuestos por el conjunto de actores presentados anteriormente (la estructura agraria), de la mano de las políticas de desarrollo que el país ha emprendido desde los noventa (el modelo de desarrollo), han tenido efectos directos en el sector rural: su productividad, niveles de ingreso ahorro e inversión, capacidad de crear empleo rural digno, su capacidad de tributar, entre otros.

De la mano de los efectos económicos sobre el sector rural, generados por estas estructuras de negociación de las relaciones en el campo, están los efectos que 
generan en el capital social rural, entendido como el "contenido de ciertas relaciones y estructuras sociales" y reflejados en "actitudes de confianza que se dan en combinación con conductas de reciprocidad y cooperación" (Cepal, 2002).

Sentimientos, emociones y conductas como el de identidad sobre el territorio, la reciprocidad o la confianza interpersonal dependen mucho de las formas como los actores hayan llegado a acuerdos vinculantes y participativos sobre asuntos comunes previamente (path dependence) (Rueda y Muñoz, 2011). Infortunadamente, en el entorno rural nacional las formas de acceder al poder político, a la tierra y demás recursos, frecuentemente se han dado mediadas por la violencia o el engaño, a través de usurpación o una combinación de medios ilegales ${ }^{6}$.

Asimismo, el campo ha sido el espacio en donde los problemas más grandes del país se reflejan y se profundizan: debilidad del Estado, conflicto armado, narcotráfico, pobreza e indigencia, corrupción y clientelismo (Perfetti, 2009). Todos estos fenómenos han influido en el debilitamiento de los niveles de confianza de los campesinos entre ellos y con sus élites, reduciendo los deseos de los campesinos de permanecer en su tierra, y a la larga alejan las posibilidades del establecimiento de cualquier clase de acuerdo a largo plazo y, por lo anterior, de cualquier organización con vocación de permanencia y estabilidad.

De acuerdo con North (1990), la estabilidad del conjunto de instituciones y normas que existen en una comunidad, siempre que faciliten el surgimiento de relaciones de confianza, determinan la posibilidad de desarrollo de instituciones y organizaciones de largo plazo. Por su parte, Axelrod (1984) destaca la tendencia de los individuos a cooperar en entornos sociales estables, donde la repetición de las interacciones entre estos será frecuente en el largo plazo. Esto, aplicado a las organizaciones objeto de estudio (asociaciones y

6 La competitividad del campo requiere, en palabras de Machado (2012), el desarrollo de una institucionalidad entendida como reglas de juego, acuerdos, organizaciones, costumbres y prácticas entre los actores del medio rural. Una institucionalidad que busque acuerdos estables entre los diferentes actores legítimos de una comunidad, como medio principal para el desarrollo social en el largo plazo. Esta institucionalidad solo será el resultado de una "construcción social" y colectiva, basada en "acuerdos para el desarrollo", a largo plazo, lo cual se da a través de la participación, la colaboración, el encuentro de complementariedades y la iniciativa de la comunidad rural. La institucionalidad debe tener en cuenta la territorialidad, entendida de manera amplia, y debe articularse desde lo local y lo nacional. cooperativas rurales), y dadas las posibilidades de que en las comunidades rurales donde estas se crean existan bajos niveles de confianza, conflictos entre las diferentes facciones del medio rural, conflicto armado, narcotráfico, poca cohesión, relaciones inestables, desarraigo y la poca o nula intención de pertenecer en el largo plazo a la misma comunidad son impedimentos de primer orden para su establecimiento y funcionamiento en el largo plazo 7 .

Es igualmente necesario hacer una breve revisión sobre el caso de asociativismo y cooperativismo rural más importante de la historia del país: el de los cafeteros. Si bien las relaciones detrás de la estructura agraria y los conflictos sociales del país tienen efectos negativos en los modelos de asociatividad rural, ¿qué factores determinaron que, en el caso de los cafeteros, la situación fuera diferente?

En el inicio de la organización cafetera, los altos precios internacionales, la aptitud de gran parte de los territorios colonizados para este cultivo, una estructura productiva por parcelas (minifundios), una relación estrecha con el Gobierno Nacional y, posteriormente, un grado alto de inserción en el modelo de industrialización por sustitución de importaciones permitieron a las familias cafeteras poderse agremiar en una organización sin par en el país ${ }^{8}$, cuyos costos de organización y dirección fueron asumidos por diferentes gobiernos nacionales, conservadores y liberales (Ocampo, 1987). Lo mismo ocurrió con las cooperativas cafeteras, ligadas a la Federación Nacional, y creadas bajo la influencia y dirección del gobierno de Carlos Lleras Restrepo (Rodríguez, 1998).

7 Es necesario destacar que la conformación de la estructura rural a lo largo del país es heterogénea; las relaciones con la tierra, su uso, entre los productores con el Estado y el mercado pueden variar entre comunidades o departamentos; los procesos sociales reivindicativos, la violencia y el narcotráfico se han dado de manera desigual en las diferentes regiones del país; las relaciones entre las élites rurales, las empresas extranjeras y las familias campesinas pueden variar de región a región. Por lo anterior, los niveles de cohesión social también pueden variar. Sobre esto, el papel del censo agrario que está desarrollando el gobierno va a ser esclarecedor, a la vez que los procesos de memoria histórica desempeñarán un papel importante en la comprensión social y comunitaria de los efectos que la confrontación compleja y profunda ha tenido en las zonas rurales, impactando la capacidad de una comunidad de establecer organizaciones sociales de gran tamaño y vocación de permanencia eficientes.

8 Según Confecoop (2008), cerca del 40\% de los activos de las cooperativas rurales se encuentra en las cooperativas cafeteras, con poco más de 79.000 asociados. 


\section{Factores internos}

Además de los elementos externos a las asociaciones y cooperativas de productores que impiden o catalizan la asociatividad rural, es necesario indagar sobre los elementos internos a estas, que les impiden o permiten desarrollar su función de manera eficiente. La siguiente sección se separará en dos unidades; la primera indagará sobre las relaciones entre el consejo de administración y la gerencia de la organización, y cómo estas pueden tener efectos positivos o negativos en la eficiencia de la empresa. En la segunda, examinará la gerencia misma y la forma en que organiza los recursos honesta y eficientemente.

\section{El papel de los asociados: los gorrones, las faccio- nes burocráticas y las estructuras de alta gerencia en las organizaciones rurales}

Se puede aceptar, como punto de partida, que un nivel alto de cohesión en un grupo de asociados impacta positivamente el desempeño de la empresa, ya sea por medio de indicaciones claras a la gerencia sobre qué debe hacer, o mediante procesos de rendición de cuentas detallados y claros. En general, en las empresas con ánimo de lucro los niveles de cohesión entre los asociados (altos o bajos) están acompañados de fuertes incentivos monetarios para que los miembros sean participativos, definan con claridad el objeto de la organización y dirijan y controlen eficientemente al gerente, pues de su capacidad para realizar estas funciones de la manera menos costosa posible depende su capacidad de controlar el rumbo de la empresa, garantizándose en el mediano plazo una parte de las utilidades logradas por la misma, representadas como dividendos. Estos incentivos monetarios desaparecen en las organizaciones rurales estudiadas, por lo cual la posibilidad de tener asociados gorrones ${ }^{9}$ (free riders)

\footnotetext{
9 El término free rider ha presentado múltiples inconvenientes al ser traducido al castellano; el autor utilizará las expresiones free rider, gorrón o no cooperador indistintamente. Sobre el uso del término castizo "gorrón", el autor se permite exponer el argumento del traductor de la edición castellana de la obra El gobierno de los bienes comunes, de Ostrom (2000): "Entre las múltiples expresiones utilizadas en español para la traducción de 'free rider', la más común es la de polizón. Aquí hemos preferido la expresión más latinoamericana de 'gorrón', porque creemos que es la que mejor capta el sentido de free rider; mientras que polizón alude a un viajero clandestino en una embarcación, 'gorrón' hace referencia a alguien que vive por cuenta de otro. De todos modos en la teoría de juegos free rider se refiere a alguien que no coopera" (Ostrom, 2000, p. $32)$.
}

y gerencias ineficientes queda ligada principalmente a los niveles de cohesión de sus asociados (a la visión comunitaria) y a las capacidades gerenciales del equipo administrativo. Los asociados gorrones en el medio rural serían quienes no asumen sus deberes en la definición de los objetivos de la organización, o en los mecanismos de control de la gerencia, pero sí desean participar de los beneficios que esta genere, los cuales pueden incluir acceso a capacitaciones, entrega de herramientas o insumos, entre otros.

En este punto, los asociados deben hacer una evaluación entre su necesidad de trabajar asociativamente en la búsqueda en el mediano y largo plazo de mejoras en la calidad de su producción, y en sus ingresos (IICA, 2013b), asumiendo a la vez costos monetarios y no monetarios en el corto plazo (el pago de la membresía y la asistencia a reuniones, la planificación, etc.).

El fenómeno de los free riders fue estudiado por Olson (1965) en su obra clásica La lógica de la acción colectiva, y se refería principalmente a los efectos que estos individuos generaban en grupos "de grandes números", dado que la presencia de gorrones en grupos pequeños se minimizará, en teoría, a causa de la posibilidad de identificar al gorrón y sancionarle, excluyéndolo de la organización y de sus beneficios. Sin embargo, el mismo autor explica que la presencia de gorrones está ligada, no solo a la cohesión social como se mencionó antes, sino también a la capacidad del grupo para controlar y sancionar eficazmente a los gorrones; es decir, pueden existir grupos relativamente pequeños en número, con actividades dispersas y de difícil control, en los que la localización y sanción de los gorrones no sea económica, ni sencilla. Este último caso se puede presentar en las organizaciones objeto de estudio.

Opuesto al problema de los asociados gorrones se encuentra el problema de la toma del poder en las organizaciones estudiadas por facciones dominantes burocráticas (llamadas roscas) (Rodríguez, 1998), las cuales tienen por práctica promover sus intereses, sin integrar los de las mayorías asociadas, negando la filosofía social, democrática y comunitaria que las organizaciones solidarias deberían representar. Estos mecanismos de poder y control terminan reproduciendo las prácticas antidemocráticas, autoritaristas y parcializadas que estas organizaciones, por su concepción, dicen defender.

Si se asume que los asociados poseen grados elevados de cohesión y espíritu de grupo (no existen gorrones ni roscas excluyentes), es decir que los gorrones serán castigados (los no cooperadores pueden ser castigados con indiferencia, negación de ayuda o la 
expulsión de la organización) y los asociados aportantes permanecerán en esta, la primera decisión que los asociados deberán tomar, en conjunto, será la estructura de la alta gerencia. Esta decisión, sobre las formas de delegar los límites del poder y de la gerencia, es estudiada por la teoría del "principal y el agente" (Cook, 1994).

\section{La alta gerencia en las asociaciones y las coopera- tivas rurales}

Además de tener estructuras de alta gerencia responsables y que impriman la transparencia, el control y la capacidad de innovación necesaria a la organización, la existencia de un gerente con altas capacidades para organizar la asociación o cooperativa rural es determinante para su desarrollo. El gerente de este tipo de organizaciones se puede definir, en primer lugar, como un "activo con alta especificidad", en palabras de Williamson (1989); es decir, los conocimientos y las capacidades desarrolladas por un gerente de una de las organizaciones estudiadas son muy específicos, y de difícil sustitución en el mercado. El gerente - de manera más general, el equipo gerencial- de una asociación rural debe, en primera instancia, ser capaz de comprender las necesidades de sus asociados, en productividad o en calidad, o en el ingreso a nuevos mercados de manera competitiva. Para lograr lo anterior, este equipo gerencial debe centralizar la oferta de bienes y servicios agrícolas de manera más competitiva que el mercado (Alchian y Demsetz, 1972). Además de saber sobre gestión de empresas, manejo de recursos humanos y económicos, planeación estratégica y sistemas de medición de la productividad, debe poseer otra serie de características. Bijman, Hendriske y Van Oijen (2012), Báez-Lacayo (2012) y el IICA (2013b) han llevado a cabo estudios en los cuales perfilan estas características. A continuación se destacan algunas de ellas:

\section{Capacidades de negociación}

Internamente, promueven consensos entre los asociados lo más rápido posible y al menor costo, fomentan la participación de la mayoría de asociados, así como resuelven conflictos de interés de la mejor manera posible. En el entorno de la organización, rastrean a los actores públicos y privados que pueden conformar una red de aliados estratégicos para él en el largo plazo y negociar con ellos bienes y servicios para la organización y sus asociados. Lo anterior requiere un equipo gerencial empático y con metas y posibilidades de desarrollo organizacional claras.
Integridad

Gran parte del desgaste del modelo cooperativista señalado al inicio del trabajo (Rodríguez, 1998) se originó por malas prácticas gerenciales: corrupción y nepotismo, que si bien no fueron generalizadas, sí han generado desconfianza en el modelo de organización cooperativista y solidaria.

\section{Conocimientos sobre el desarrollo rural}

La agricultura es un sector económico con dinámicas muy diferentes a las que tienen los demás sectores de la economía; la riqueza creada depende de la naturaleza misma: la tierra y los ciclos naturales. Las características técnicas (físicas y químicas) de los suelos, el papel de los climas y los posibles riesgos naturales, las dinámicas de los mercados internacionales y la organización de la estructura agraria son elementos determinantes de los índices de crecimiento y desarrollo del sector, con los cuales debe estar relacionado el equipo gerencial de una organización rural. Justamente, en el conocimiento profundo de la ruralidad es que se pueden fomentar modelos innovadores de negocio y de emprendimiento (Parrado, 2010).

\section{Visión comunitaria}

Es necesario recordar que las organizaciones estudiadas, si bien son gremiales y empresariales, se fundan buscando el mejoramiento de las comunidades en las cuales operan; la fortaleza comunitaria es en sí misma un insumo de estas organizaciones, mucho más en el entorno rural colombiano, tratado anteriormente. La gerencia de estas organizaciones debe estar conformada por líderes comunitarios, que conozcan los problemas de sus comunidades, y sean un puente entre esta y la organización. Igualmente, deben emprender procesos de vinculación de las generaciones más jóvenes en el fortalecimiento de las organizaciones y las comunidades, tratando de evitar las migraciones a la ciudad y el abandono de los minifundios.

\section{Factores internos y externos que inciden en la asociatividad rural: Viotá}

Esta sección desarrolla una descripción de los factores externos e internos que favorecen o limitan sus capacidades de eficiencia y permanencia en las asociaciones rurales de Viotá, Cundinamarca. Inicialmente se 
presentará la metodología a través de la cual se accedió a la información. Luego se presentarán los factores externos, representados en la estabilidad de la estructura rural, seguidos de los factores internos, dependientes de la estructura y del funcionamiento de cada una de las organizaciones rurales estudiadas. A manera de cierre, se hará un balance entre los factores externos e internos, los principales retos de estas nacientes organizaciones para seguir en funcionamiento y ampliar su capacidad de estabilización de la estructura rural.

\section{Descripción de aspectos metodológicos}

El siguiente análisis sobre los factores internos y externos de las asociaciones rurales se logró a través de revisión de informes sobre el municipio, para comprender el estado de la estructura rural, además de visitas en sus parcelas y entrevistas a las familias campesinas (de acuerdo con el concepto de familia campesina de Lowder, Skoet y Singh, 2014) vinculadas al proyecto ${ }^{10}$; y entrevistas a los presidentes de tres asociaciones rurales de la región.

En las visitas se indagó acerca del tamaño y el estado de las parcelas y su uso productivo; en las entrevistas a las familias campesinas se averiguó sobre:

1. El tamaño de la unidad familiar;

2. El perfil del hombre o mujer cabeza de familia: sus niveles de estudios, años de experiencia en las actividades agrícolas, y sus principales redes sociales;

3. El estado de los cultivos: los principales problemas que ha tenido en el manejo de las parcelas y sus proyectos comerciales en los próximos dos años;

4. Si la familia campesina cuenta o no con algunos requisitos legales (como escrituras, registros tributarios o mercantiles, seguridad social), $y$

5. Si se encuentra asociado o no, y los motivos por los cuales ha decidido o no trabajar de manera asociada.

En las entrevistas realizadas a los presidentes, vocales o secretarios de las tres organizaciones rurales se investigó sobre:

1. La razón de ser de la asociación: la forma en la que fue creada, el número de asociados a esta y su participación en asambleas y puntualidad en el pago de los derechos de membresía;

10 Se realizaron ocho visitas en total, entre el 15 de mayo y el 15 de diciembre del 2014.
2. El perfil de quien la administra, o del equipo administrativo en caso de haberlo: su nivel de estudios, experiencia en el medio rural y redes de trabajo;

3. Los principales problemas internos y externos de la asociación, sus proyectos en curso y su visión a dos años, $y$

4. Cuál es el grado de formalidad de la organización rural: si esta tiene documentos de creación, tributarios, actas y estatutos actualizados. Para comprender los factores externos a las organizaciones rurales se recurrió a informes proporcionados por la alcaldía municipal, además de las encuestas mencionadas a las familias campesinas. La descripción de los factores internos se hará tomando como base las tres asociaciones rurales encontradas ${ }^{11}$.

\section{Factores de la estructura rural y el capital social que perfilan el desarrollo de organi- zaciones rurales estables y eficientes en el territorio de Viotá}

El municipio de Viotá está ubicado en la parte sur de la Provincia del Tequendama, Cundinamarca; se integra regionalmente a los municipios de Quipile, Cachipay, La Mesa, Tena, San Antonio, El Colegio y Apulo. Está habitado por 12237 personas, de las cuales 50,34\% son mujeres y $49,66 \%$ son hombres. De la población total del municipio, el 33,7\% es menor de edad, el 46,7\% está entre los 18 y los 59 años de edad, y un 19,5\% es población mayor de 60 años (Consejo Municipal de Viotá, 2012).

El municipio tiene 20.567 hectáreas rurales aproximadamente, de las cuales 14.560 corresponden a pequeños productores con minifundios menores de 5 hectáreas. Las 6.107 Hectáreas restantes, son explota-

11 La metodología desarrollada permite una aproximación inicial del conjunto de factores internos y externos. Para una comprensión global e integral de los factores externos que influyen en las asociaciones rurales sería necesario tener datos sobre la evolución de la estructura agraria de la región en la última década, los usos de los suelos (agrícolas o ganaderos y de qué clase), los movimientos demográficos, los cambios en las formas de división de la tierra, kilómetros de vías construidas, etc. Así mismo, contar con informes de memoria histórica sobre los efectos del conflicto armado que vivió la región en la estructura de las élites rurales y políticas, en las relaciones entre las diferentes facciones del medio rural, en los niveles de confianza interpersonal y de arraigo de los pobladores con el municipio. Paralelamente, sobre los factores internos, el grupo de investigadores tuvo acceso solamente a tres asociaciones rurales de la región. Lo anterior no supone inconvenientes metodológicos, pues los factores internos se presentarán de manera independiente, dado que cada organización tiene singularidades relevantes. Las similitudes encontradas serán presentadas por las tres organizaciones, para reducir el texto y sin propósitos de generalización. 
ciones mayores. El 67,8\% del sector rural se dedica con exclusividad a las labores agrícolas (Consejo Municipal de Viotá, 2012, p. 123).

Asimismo, del total de hectáreas del municipio, 2667 son rurales, y solo 133 son urbanas (Consejo Municipal de Viotá, 2012, p. 75). El trabajo agrícola se realiza con tecnologías tradicionales, intensivas en mano de obra familiar, de menos de cinco integrantes; en épocas de cosecha se contrata mano de obra (\$25000 jornal). Los cultivos más importantes de la región son el café, el cacao, el aguacate, y los cítricos; cada una de estas actividades tiene al menos una organización (asociación de productores) que las representa. Sobre la presencia de otras actividades del sector primario, la ganadería ha ganado importancia en la región (Consejo Municipal de Viotá, 2012, p. 131).

De acuerdo con lo anterior, se puede afirmar que la estructura agraria del municipio se caracteriza por las pequeñas parcelas, trabajadas por familias campesinas; estas no venden su fuerza de trabajo a otras unidades productivas. No se evidenciaron relaciones entre arrendatarios y propietarios, que sí se presentan en otros contextos rurales.

Las relaciones de las familias campesinas con los mercados (distribuidores y compradores) se pueden comprender a través de la geografía. Viotá está ubicado sobre el piedemonte de la Cordillera Oriental, principio de abundancia de climas y suelos, y principio también de un sistema de comunicación difícil entre las veredas y entre las familias campesinas con el casco urbano, mediado por un territorio montañoso con vías terciarias curvas y escarpadas, típicamente en mal estado. Asimismo, en el casco urbano, no hay un centro de acopio general de mercancías, ni infraestructura para la comercialización, sí está el Comité de Cafeteros de Viotá.

Por lo anterior, varias familias campesinas (no cafeteras) venden su producción a compradores pequeños o medianos, intermediarios que van de parcela en parcela con sus vehículos particulares; excepcionalmente transportan la mercancía desde las parcelas al casco sin tener un comprador asegurado, evitando asumir costos de transporte que puedan ser irrecuperables. Particular es el caso de los cafeteros vinculados con la Federación, que acuden a la sede mencionada. Ninguna de las familias campesinas entrevistadas vende su producción a la Central de Abastos de Bogotá o a sus intermediarios; principalmente por los precios que establecen los compradores.
En relación con la infraestructura de riegos y drenajes, esta es escasa. Para muchas familias, el acceso a agua de riego constante depende de la presencia de un río o quebrada colindante con las parcelas o de la posibilidad de poder cavar un pozo (la infraestructura de acueductos veredales no es universal).

Sobre las relaciones de las familias campesinas con la institucionalidad rural, la organización más cercana a estos es el Banco Agrario de Colombia, el cual les otorga préstamos típicamente para la adquisición de plantas; esto se puede dar en virtud de que numerosas familias tienen los títulos de propiedad de sus parcelas, y con ellos pueden dar soporte a los créditos. Por su parte, la Alcaldía y el Consejo Municipal (Consejo Municipal de Viotá, 2012) han señalado el compromiso de promover la asociatividad, el emprendimiento rural y el diálogo directo con los representantes de las asociaciones campesinas. Acerca de ese tema, las perspectivas están enfrentadas, porque si bien algunos campesinos dicen no tener acceso a los representantes del gobierno municipal, ni posibilidad de ser oídos por sus concejales ni gobernantes, existen otros que tienen redes cercanas a estas instituciones. Las capacidades dispares de acceder a estas instancias casi siempre se explican por la pertenencia o no a algún círculo de la élite rural.

Desde finales del siglo XIX hasta mediados del siglo $\mathrm{xx}$, Viotá fue escenario de constantes luchas políticas, las cuales permitieron a las familias campesinas adquirir los títulos de sus propias parcelas, liberándose de las relaciones de arrendamiento propias de las grandes haciendas del siglo anterior, perfilando la región como una comunidad agrícola de micropropietarios, hecho sui géneris en la historia agraria nacional. Por oposición el territorio también padeció, a inicios del siglo, una escalada de la violencia por las pugnas de poder entre los actores alzados en armas (paramilitares y guerrilleros), lo cual obligó a numerosas familias campesinas a abandonar sus territorios para evitar ser asesinadas o secuestradas. Esta historia está por escribirse.

\section{Asociaciones rurales de Viotá: factores internos para su estabilidad y eficiencia}

En la presente sección se presentarán los factores internos que afectan las capacidades de permanencia y eficiencia de las asociaciones rurales, en términos de estructuras débiles o fuertes de alta gerencia, de las capacidades gerenciales para medir la productividad de la organización, diseñar y ejecutar los proyectos futuros de la organización, medir la productividad de esta, 
generar cohesión entre los asociados y establecer redes de valor con el entorno. Para lograr este objetivo inicialmente se describirá el papel que tiene la asociatividad para las familias campesinas; luego se describirán los tres casos localizados en Viotá: Asociación de Cacaoteros del Bajo Tequendama (Ascabate), Asociación de Cafés Especiales de Viotá (Asocavi) y Asociación de Productores Cafeteros de Viotá (Aprocavi), sus similitudes y sus diferencias.

\section{El papel de la asociatividad para las familias cam- pesinas}

La gran mayoría de los productores que participaron en el proyecto pertenece a alguna asociación, reconoce que es importante para ellos estar vinculados a estas y expresa estar en contacto con otros productores rurales. En el momento de declarar el objetivo que tienen al asociarse, la formación en capacidades técnicas para mejorar las prácticas de manejo de sus cultivos (impactando la calidad y la productividad) sobresale como respuesta. Asimismo, un grupo menos numeroso de productores indica que la asociatividad puede serles útil como medio para procesos de comercialización. Esto es un indicio de que los productores agrícolas reconocen que, en razón de que la productividad de las parcelas es baja, y sin capacidad productiva ni calidad de producto, invertir en estrategias de ingreso al mercado sería inadecuado.

A propósito de los procesos de asociatividad intentados en el pasado, admiten la existencia de asociaciones que no pudieron permanecer en funcionamiento por problemas de alta gerencia, en primer lugar por problemas de captura del poder de la organización por algunas familias (nepotismo), que dirigieron la organización sin sentido solidario, no entregaron cuentas a los asociados sobre sus actividades y utilizaban los recursos de la organización como medios para mantener su poder (a través de cuotas burocráticas o entrega de recursos); en segundo lugar, por la presencia mayoritaria de asociados gorrones (no cooperadores), los cuales no asumían sus responsabilidades (en entrega de aportes, asistencia a asambleas, etc.), pero sí participaban de los beneficios logrados por esta asociación (desarrollo de capacitaciones, entrega de herramientas). En los dos casos, la debilidad del cuerpo de asociados no pudo controlar la expansión de estos fenómenos debilitadores de la asociación, que finalmente terminaron minando la confianza de los productores en los procesos asociativos.
En el cuerpo de asociados se deben establecer dos fenómenos que se presentan en la región (además de los mencionados problemas de gorrones y roscas): primero, la imposibilidad de los asociados de participar en las asociaciones por falta de conocimiento sobre cómo direccionar una organización como estas, y segundo, la imposibilidad de asumir su papel como asociado a causa de la inestabilidad, inseguridad y alto riesgo de perder los ingresos a los que están sometidos estos productores rurales. Sobre el primer problema, este se fundamenta en el desconocimiento de las formas de organización social que existen, al igual que sobre estrategias de control de sus pares asociados y de la gerencia (problema principal-agente). El segundo problema radica en el alto grado de vulnerabilidad de las familias campesinas de perder una cosecha; los sistemas productivos son intensivos en mano de obra; los sistemas de riego y drenaje, escasos; la aplicación de las mejores prácticas técnicas de cultivo es precaria (se conoció más de un caso en el que a una misma familia campesina y parcela dos ingenieros agrónomos de diferentes organizaciones les recomendaron técnicas de cultivos diferentes) y hace que las familias campesinas deban permanecer en sus fincas, todos los días, durante la mayoría de las horas de trabajo. Este es un factor adicional que dificulta la creación de aglomeraciones que trabajen de manera continua y que puedan contribuir a la organización de manera estable en el tiempo, a manera de aportes.

En relación con el nivel de acceso a servicios de salud básicos en las familias campesinas, se pudo establecer que la vinculación a sistemas de protección social en salud es generalizada (pero no universal): Sisben y EPS, como cotizantes o subsidiados (relación de 7 cotizantes a 1 subsidiado). La mayoría de productores acepta haber tenido pérdidas de las cosechas en los últimos dos años: el clima o las plagas, falta de mano de obra para el manejo de las plantas, conocimiento técnico sobre su cuidado, o incapacidad de encontrar redes de comercialización del fruto. Todas estas causas pueden ser mitigadas a través de infraestructura (vías y sistemas de riego), conocimientos técnicos en agronomía y redes de comercialización; algunos productores están en periodo de espera de que las plantas den la primera cosecha ${ }^{12}$, después del repoblamiento del municipio, pasada la confrontación armada; otros han perdido de manera

\footnotetext{
12 El cacao es un cultivo en proceso de introducción y expansión en la región, con tres o cuatro años de espera para la primera cosecha, de las plantas sembradas este año.
} 
consecutiva por dos años la cosecha, y han cambiado su actividad económica de la agricultura a otras, típicamente el comercio o trabajos de servicio doméstico, para poder solventar los gastos de la familia.

\section{Ascabate, Asocavi y Aprocavi}

A continuación, se describirán las tres asociaciones a las cuales se tuvo acceso; inicialmente se presentarán los elementos que tienen en común, y posteriormente, sus diferencias. En cuanto a las organizaciones, se hará énfasis en: sus fines, las actividades efectivas de sus gerencias para lograr la misión y la visión de la organización, para gestionar redes que agreguen valor a las actividades y para generar cohesión entre sus asociados.

Ascabate, Aprocavi y Asocavi son asociaciones con fines gremiales, empresariales y de mercado. $\mathrm{Su}$ origen y sus fines están directamente relacionados con generar mejores condiciones de acceso al mercado para las familias campesinas asociadas. Las tres se reúnen en el casco urbano del municipio ${ }^{13}$, en la única infraestructura central y habilitada para una agremiación numerosa de campesinos: la sede del Comité de Cafeteros de Viotá (entidad que les presta la sede para este fin, de acuerdo con su disponibilidad). El presidente y los vocales de las asociaciones a los que se tuvo acceso reconocen la importancia del principio de "separados débiles, juntos fuertes", la organización de las familias campesinas para resolver problemas comunes y aprovechar oportunidades de mercado, los cuales, desagregados, no podrían enfrentar.

La mejora de calidades, el aumento de la productividad y la exploración de mercados de alto valor son procesos que involucran directamente la transformación de los modos de producción de las familias campesinas, las cuales se pueden encontrar tomadas por la hojarasca, sin acceso a riegos ni drenajes, con herramientas e infraestructura precarias; además, los propietarios usualmente no tienen sus registros como comerciantes y agricultores ante la Cámara de Comercio ni la DIAN, ni los registros más básicos de egresos e ingresos obtenidos por la unidad productiva. La fortaleza de estas asociaciones se logra con el fortalecimiento de las parcelas asociadas y viceversa.

13 Para muchas de las familias campesinas (asociadas o no), acceder al casco urbano no es una actividad sencilla: en razón a la geografía montañosa, el estado precario de las vías terciarias y el escaso transporte público, el acceso al dicho caso puede tomar más de dos horas en vehículo (especialmente para las veredas más alejadas o en zonas de difícil acceso).
Las tres asociaciones fueron formadas después de los años de confrontación entre los actores armados que padeció el territorio; por esta razón, tienen menos de diez años de funcionamiento. Según lo analizado en este trabajo, son asociaciones jóvenes. Para el largo plazo, pretenden desarrollar actividades de transformación, distribución y acopio de sus diferentes bienes agrícolas alrededor de empresas cooperativas, las cuales tendrían como insumo las actividades de mejora logradas por las asociaciones en marcha. Finalmente, en las tres se evidencia la importancia de que al menos una organización privada o pública (Federación Nacional de Cafeteros, Fedecacao y la Alcaldía municipal) las promueva activamente a través de la entrega de tecnologías blandas o duras.

Si bien en el territorio no se encontró ninguna cooperativa, las tres asociaciones expresaron su interés en el mediano plazo de poder agremiarse alrededor de una empresa de producción agrícola de este tipo. El desarrollo de cooperativas rurales fuertes depende de los factores internos y externos indicados por Mendoza et al. (s. f.), IICA (2010) e IICA (2013a), y resumidos en la primera parte del documento: desarrollar procesos de largo plazo, integración entre poderes locales y a la academia, para el fomento y soporte en temas legales, comerciales, de propiedad intelectual, investigación y desarrollo financieros, entre otros.

\section{Ascabate}

Fundada en 2012, agremia a cerca de 65 productores de cacao. El objetivo de esta organización es mejorar los procesos de cultivo de cacao en las parcelas asociadas. El apoyo del sena y también el de la Federación Nacional de Cacaoteros han sido primordiales en su fundación y consolidación; la primera apoyó los procesos de constitución legal y las capacitaciones en economía solidaria; la segunda aporta asesoría técnica agronómica y plántulas de cacao.

Las reuniones de asociados se dan mensualmente, y el porcentaje de asistencia está entre el 25 y el 50\% aproximadamente. Los asociados se reúnen para: primero, recibir clases de cultivo, aportadas por la Federación; segundo, asistir a sesiones ordinarias de planeación y control, y tercero, para realizar actividades de cohesión entre los asociados (por ejemplo, reunirse para almorzar).

Los principales problemas de la organización, según su presidente, son: la falta de pertenencia de sus asociados, como problema interno; la ausencia de un 
lugar de reunión propio, una sede propia, lo cual limita la autonomía de la organización y su capacidad de convocatoria. El ingreso a Ascabate tiene un costo de $\$ 20000$, con mensualidades de $\$ 6000$. El objetivo de estos recursos es adquirir herramientas para los asociados. En esta distribución de herramientas, se ha privilegiado la antigüedad y participación de los asociados como criterio de asignación.

Los problemas de asociados gorrones se presentan en esta asociación, pues existe un conjunto de no cooperadores, no identificados, que participa de la asociación cuando esta entrega capacitaciones $\mathrm{u}$ herramientas, pero que no asiste a asambleas generales ni está al día con el derecho de membresía. La presidencia de esta asociación se preocupa por mejorar los niveles de cohesión y participación entre los asociados, realizando reuniones informales y capacitaciones en asociatividad.

Finalmente, no se evidenciaron mecanismos de control y de eficiencia de la organización y sus actividades: sobre las capacitaciones realizadas, no se llevan controles de asistencia, ni se controla que las familias asociadas estén realmente implementando las mejores prácticas aportadas por la Federación. Los asociados siguen asistiendo a estas, dado que no tienen formas externas de capacitarse de manera gratuita y de acuerdo con su disponibilidad de tiempo; sin embargo, la productividad de estas capacitaciones no se mide ni se controla. Por lo anterior, los proyectos de mejora de las calidades y productividades (y el posterior ingreso a mercados de alto valor) no se gestionan ni dirigen controladamente.

\section{Asocavi}

Fundada en 2013 y con cerca de 70 asociados, sus objetivos son producir y comercializar cafés especiales y revitalizar las tradicionales haciendas cafeteras. La organización cuenta con asistencia mayoritaria a las asambleas (más del 70\% de asociados). Su mesa directiva está compuesta por miembros de algunas familias reconocidas de la región, quienes además de poseer capacidades técnicas y niveles de formación superiores a los de las demás familias campesinas vinculadas (abogado, ingeniero agrónomo, arquitecto, entre otros), tienen cercanía a algunas instituciones académicas y de poder local (gobierno y cabildo municipal, facultades de agronomía y laboratorios).

Sobre los procesos de certificación del café y las fincas, algunos asociados están trabajando en ese sentido con laboratorios internacionales, sin que sea una política general de la asociación. En cuanto a las actividades enfocadas a la revitalización de las haciendas cafeteras, estas son grandes estructuras de finales del siglo XIX (casas y beneficios), en las cuales se procesaba el café en sus años de auge e introducción al campo colombiano. Son en sí mismas un patrimonio de la agricultura nacional, pues reflejan los primeros pasos de la industrialización en Colombia (muchas de ellas tienen instaladas máquinas importadas de Estados Unidos) y permiten comprender las primeras formas de organización económica, social y política alrededor del grano. Sobre su estado de conservación, muchas de estas infraestructuras están en pie, algunas de ellas todavía con la capacidad de funcionar, lo cual es sorprendente si se tiene en cuenta que la región fue el escenario de numerosas confrontaciones en el último siglo. Los propósitos de sus propietarios sobre esta infraestructura es desarrollar industrias culturales alrededor de estas (museos y centros de formación en cultura cafetera), en los cuales la historia regional (y nacional) se conserve y se difunda. Sin embargo, el desarrollo del proyecto se vislumbra lejano, dado que las inversiones en reconstrucción del patrimonio material e inmaterial son elevadas y requieren la conjunción de diferentes actores especializados (historiadores, curadores, restauradores, arquitectos, además de las instancias públicas). Además, la decisión de llevar a cabo actividades culturales y de turismo, paralelo al cultivo y comercialización de cafés especiales, exige ponderar si la infraestructura de las antiguas haciendas cafeteras puede ser útil para producir cafés con los requerimientos técnicos, o si estas deben ser modificadas, y si esto no reduce el valor patrimonial de estos bienes.

La organización ya cuenta con una torrefactora de café, aportada de manera conjunta con la municipalidad (que entregó maquinaria a otras asociaciones de la región), la cual les permitirá centralizar los procesos de transformación del grano, y evaluar la posibilidad de ofrecer servicios a otros productores de la región. La asociación no se reúne de manera periódica, y no hay evidencia de que ejerza actividades de control y dirección de las actividades de tecnificación en función del desarrollo y venta de cafés especiales.

\section{Aprocavi}

Fundada en 2005 y con cerca de 20 asociados en Viotá Esta asociación fue una de las primeras en ser creadas pasada la escalada paramilitar en la región y las confrontaciones entre los diferentes actores armados. 
Surgió por iniciativa de la Federación Nacional de Cafeteros y la municipalidad, como un mecanismo de respuesta al despoblamiento y abandono de las parcelas del municipio, con el fin de reintegrar las familias cafeteras a las actividades del campo, de manera productiva, garantizándoles entrega de plantas, asesoría técnica y comercialización. En su primera etapa, se desarrollaron actividades por parte de la Federación y la municipalidad, de la mano de trabajadores sociales, para reintegrar a las familias campesinas al campo, y evaluar los efectos sociales y comunitarios que generó la guerra en sus asociados.

Los procesos de aglutinación de asociados y de fortalecimiento de la economía cafetera han sido lentos; para tener diez años de funcionamiento, el número de asociados en la región son pocos; las actividades de cultivo están mediadas por nuevas especies de café, las cuales tienen manejos especiales y desconocidos por los asociados, de la mano de declaraciones de desconfianza sobre el trabajo de la Federación que, en boca de algunos cafeteros, ha entregado especies nuevas, más delicadas y que requieren prácticas de cultivo opuestas a las tradicionales de la región.

Los precios del café se mantienen bajos con respecto al de otros cultivos para los cuales tiene vocación la región (como el aguacate); a causa de esto muchas familias campesinas prefieren reemplazar sus cultivos. Por su parte, la asociación propone en el mediano plazo adquirir y poner en funcionamiento una central de beneficio, ubicada en la sede del Comité, para concentrar las actividades de transformación del grano, que actualmente se desarrollan de manera descentralizada.

\section{Conclusiones}

La presencia de una comunidad numerosa y homogénea, como lo son las familias campesinas viotunas (con similitudes en tamaño de la unidad familiar y de la parcela, tipos de cultivos y problemas comunes) es un factor a favor del origen de asociaciones rurales, pues estas pueden identificarse reconociendo que trabajando de manera aglutinada pueden ser más eficientes en progresar que de manera independiente; sin embargo, el papel del conflicto armado y sus incidencias en los niveles de confianza interpersonal entre facciones de la comunidad rural puede operar en contra de la asociatividad, así como el interés de los ciudadanos de participar en procesos políticos, a causa del desencanto. La geografía, la poca comunicación que existe entre las familias campesinas, producto de una geografía difícil y unas vías de comunicación precarias, constituyen otro factor de la estructura rural para tener en cuenta.

El conflicto armado, al generar desplazamiento y abandono de las parcelas, terminó por desmembrar a las asociaciones rurales existentes a finales de siglo, haciendo necesario volver a iniciar desde cero los procesos de organización; igualmente las parcelas quedaron abandonadas durante media década, perdiéndose los cultivos y siendo reclamadas por la naturaleza (por la maleza o la hojarasca), y requieren una inversión en trabajo y capital extra para poder ponerlas en marcha a toda su capacidad. La inversión en política social que permita sanar las heridas y fortalecer el tejido social puede tener efectos positivos en el empoderamiento y en el trabajo en equipo, bases del asociativismo solidario.

La existencia de asociados no cooperadores, miembros de facciones burocráticas excluyentes, subpreparados para las actividades de control y dirección, o con realidades económicas precarias son factores en contra del desarrollo de asociaciones fuertes. Gerencias con problemas de control y medición de los procesos misionales de la organización, como la mejora técnica o actividades generadoras de cohesión, no operan a favor de asociaciones con permanencia.

Como balance final, las asociaciones poseen una estructura agraria estable para desarrollarse, después de varios años de conflicto. A diferencia de otras latitudes, Viotá no presenta conflictos armados, ni conflictos mineros o ganaderos; las titulaciones fueron resueltas hace varias décadas. Los problemas internos, referidos a la agencia "asociados-gerencia", pueden ser aún más relevantes: asociados sin capacitación en organización solidaria, en estado de alto riesgo vital o no cooperadores (problemas que típicamente se mitigan a través de la capacitación, la formación en asociativismo y con arreglos contractuales claros, en los cuales los derechos, las sanciones y los controles sean efectivos, o con fondos mutuales de apoyo a los más vulnerables), siguen vigentes en la región; de la mano, la carencia de altos niveles de formación gerencial requeridos para poder controlar, medir y gestionar los procesos de las organizaciones, sean estos enfocados al mercado u orientados a mejorar los niveles de cohesión, haciéndolas funcionales en la forma, pero insostenibles por improductividad.

El presente trabajo establece un marco de estudio sobre los factores internos y externos a la organización rural que impactan su eficiencia y vocación de largo 
plazo. Este enfoque amplía la perspectiva de las teorías eminentemente microeconómicas que afirman que el desarrollo rural se puede dar mejorando únicamente las capacidades de los campesinos en gestión, convirtiendo al "campesino en empresario" (Tobasura, 2009), sin tener en cuenta el entorno.

El enfoque propuesto se basa en teorías clásicas del neoinstitucionalismo económico: la eficiencia y vocación de largo plazo de una organización de mercado (como lo son las cooperativas y las asociaciones rurales estudiadas) dependen de su capacidad efectiva de reducir los costos de transacción (Coase, 1937); esta reducción, así mismo, se da si el gerente logra medir internamente la productividad de la organización (Alchian y Demsetz, 1972), y externamente con entornos estables (North, 1990) y en comunidades con un grado alto de cohesión y capacidad de autoorganización (Ostrom, 2000). Es acompañada con estudios sobre la estructura agraria, el capital social rural, modelos de desarrollo de asociaciones rurales en América Latina y teorías del papel de la gerencia en organizaciones rurales.

\section{Agradecimientos}

A los profesores Juan Gabriel Gómez Albarello, Leonardo Briceño, Julián y Eduardo Gutiérrez y Diana Páez, quienes leyeron los diferentes borradores del presente texto y me ofrecieron valiosos comentarios, mis agradecimientos.

\section{Referencias}

Alchian, A. y Demsetz, H. (1972). Production, Information Costs, and Economic Organization. American Economic Review, 62, 777-795.

Axelrod, R. (1984). The Evolution of Cooperation. Ann Arbor: University of Michigan Press.

Báez Lacayo, L. (2012). El contexto y principales características de las cooperativas y desafíos. En FAO, Cooperativas campesinas y seguridad alimentaria: un modelo vigente. Roma, Italia: FAO.

Bejarano, J. (1998). Una política comercial de transición para la agricultura. Cuadernos de Economía, 28(xviI), 181235.

Bijman, J., Hendriske, G. y Van Oijen, A. (2012). Accommodating Two Worlds in One Organization: Changing Board Models in Agricultural Cooperatives. ERIM Report Series Research in Management.
Castro-Rodríguez, L. (1963). Las cooperativas del campo y el mercadeo de los productos agrarios. Revista de Estudios Agrosociales, 44, 99-118.

Centner, T. J. (1988). The Role of Cooperatives in Agriculture: Historic Remnant or Viable Membership Organization? Journal of Agricultural Cooperation, 3, 94-106.

Cepal. (2002). El capital social campesino en la gestión del desarrollo rural. Diadas, equipos, puentes y escaleras. Santiago de Chile: Comisión Económica para América Latina y el Caribe (Cepal).

Coase, R. (1937). The Nature of the Firm. Economica, New Series, 4(16), 386-405.

Confecoop. (2008). Sector cooperativo agropecuario colombiano. Observatorio Cooperativo, 6.

Consejo Municipal de Viotá. (2012). Plan de Desarrollo. Viotá territorio de paz y prosperidad 2012-2015.

Cook, M. L. (1994). The Role of Management Behavior in Agricultural Cooperatives. Journal of Agricultural Cooperation, 9, 42-58.

Coque-Martínez, J. (2002). El cooperativismo rural en zonas desfavorecidas: una panorámica de los orígenes y situación actual en África, Asia y los antiguos países socialistas del este de Europa. Cuadernos de Desarrollo Rural, 47, 9-53.

Dávila, R. (2004). Innovación y éxito en la gerencia cooperativa. Bogotá: Pontificia Universidad Javeriana.

Demsetz, H. (1997). La competencia. Madrid: Alianza Editorial.

FAO. (2012). Las cooperativas agrícolas alimentan al mundo. Roma, Italia: FAO.

Fajardo, D. (s. f.). Tierra, poderío político y reforma agraria y rural. Cuadernos Tierra y Justicia, 1. Disponible en: http://www.kus.uu.se/CF/Cuaderno_01.pdf

Foronda-Robles, C. y Galindo-Pérez de Azpillaga, L. (2012). Argumentación relativa a la confianza territorial. Claves sobre capital social. Cuadernos de desarrollo rural, 9(68), 41-63.

Gómez, H. J. (2011). Política comercial y de competitividad del sector agrícola en Colombia. En Fedesarrollo. La política comercial del sector agrícola en Colombia. Cuadernos de Fedesarrollo, 38, 1-9.

Hellin, J. y Higman, S. (2002). Los pequeños agricultores y los mercados especializados: Lecciones aprendidas en la Región Andina. Documento de trabajo número 118. Red de Extensión e Investigación Agrícola.

IICA. (2010). Un nodo de cooperación sobre la experiencia de Costa Rica en cooperativas agrícolas. San José: IICA.

IICA. (2013a). Innovaciones de impacto: lecciones de la agricultura familiar en América Latina y el Caribe. San José: IICA. 
IICA. (2013b). Orientaciones estratégicas para el fortalecimiento de la gestión asociativa. San Salvador: IICA.

ILSA. (2012). Zonas de Reserva Campesina. Elementos introductorios y de debate. Bogotá: Gente Nueva Editorial, ILSA.

International Co-operative Alliance. (s. f.). What is a Co-operative? Bruselas: International Co-operative Alliance. Recuperado de http://ica.coop/es/node/10584

León, M. G. (2010). Evaluación de la asociatividad como una herramienta de competitividad en la cadena de valor del cuero. Caso Curtiembres de Villapinzón y Chocontá. Bogotá: Universidad Nacional de Colombia.

Lowder, S. K., Skoet, J. y Singh, S. (2014). What do we really know about the number and distribution of farms and family farms in the world? Background paper for The State of Food and Agriculture 2014. ESA Working Paper No. 14-02. Rome, FAO.

Machado, A. (2012). El desarrollo rural y la institucionalidad. Revista Hechos de Paz. PNUD, 64, 18-20.

Mendoza, R., Gutiérrez, M. E., Pedraza, M. y Fernández, E. (s. f.). Las cooperativas de café en Nicaragua: ¿Disputando el capital del café a las grandes empresas?

Ministerio de Agricultura y Desarrollo Rural. (2006). Apuesta Exportadora Agropecuaria 2006 - 2020. Bogotá: Ministerio de Agricultura y Desarrollo Rural.

Misas, G. (2002). La apertura de los noventa. Del gradualismo al colapso. Bogotá: Universidad Nacional de Colombia.

Nash, J. (2011). Estado actual y tendencias de los mercados agrícolas globales. En Fedesarrollo. La política comercial del sector agrícola en Colombia. Cuadernos de Fedesarrollo, 38, 23-46.

North, D. (1990). Instituciones, cambio institucional y desempeño económico. México: Fondo de Cultura Económica.

Ocampo, J. A. (Comp.). (1987). Historia económica de Colombia. Bogotá: Siglo XXI Editores.

Olson, M. (1965). The Logic of Collective Action: Public Goods and the Theory of Groups. Cambridge: Harvard University Press.

Osejo-Varona, A. (s. f.). Zona de Reserva Campesina: política pública y estrategia para la defensa de territorios.
Recuperado dehttp://www.indepaz.org.co/wp-content/ uploads/2013/04/Zona_de_Reserva_Campesina_Politica_publica_y_estrategia_para_la_defensa_de_territorios_campesinos.pdf

Ostrom, E. (2000). El gobierno de los bienes comunes: la evolución de las instituciones de acción colectiva. México: Fondo de Cultura Económica.

Parrado, Á. (2010). From the Associative Companies to the Nuclei of Rural Entrepreneurs. Agronomía colombiana, 28(3), 487-492.

Perfetti, J. J. (2009). Crisis y pobreza rural en América Latina: el caso de Colombia. Documento de Trabajo n. ${ }^{\circ} 43$. Programa Dinámicas Territoriales Rurales. Santiago, Chile: Rimisp.

Perfetti, J. J. (2011). Oferta potencial agrícola de Colombia en un nuevo entorno de mercado. En Fedesarrollo. La política comercial del sector agrícola en Colombia. Cuadernos de Fedesarrollo, 38, 103-133.

PNUD. (2011). Colombia rural. Razones para la esperanza. Informe Nacional del Desarrollo Humano. Bogotá: INDH PNUD.

Reina, M., Zuluaga, S., Bermúdez, W. y Oviedo, S. (2011). Protección e incentivos agrícolas en Colombia. En Fedesarrollo. La política comercial del sector agrícola en Colombia. Cuadernos de Fedesarrollo, 38, 75-101.

Restrepo, J. C. (2011). Política integral de tierras: sector agropecuario locomotora de crecimiento. En Fedesarrollo. La política comercial del sector agrícola en Colombia. Cuadernos de Fedesarrollo, 38, 11-21.

Rivera, C. F. (1999). El problema agrario: una crisis epistemológica. Cuadernos de Economía, 31 (vvxvini), 281-300.

Rodríguez-Vargas, F. (1998). Organizaciones de productores de café en el sector cooperativo. Innovar, 11, 39-63.

Rueda, M. y Muñoz, J. (2011). Asociatividad, capital social y redes de innovación en la economía rural. Gestión y Sociedad, 27-41.

Tobasura, I. (2009). De campesinos a empresarios: la retórica neoliberal de la política agraria en Colombia. Agronomía, 17(1), 21-34.

Williamson, O. (1989). Las instituciones económicas del capitalismo. México: Fondo de Cultura Económica. 